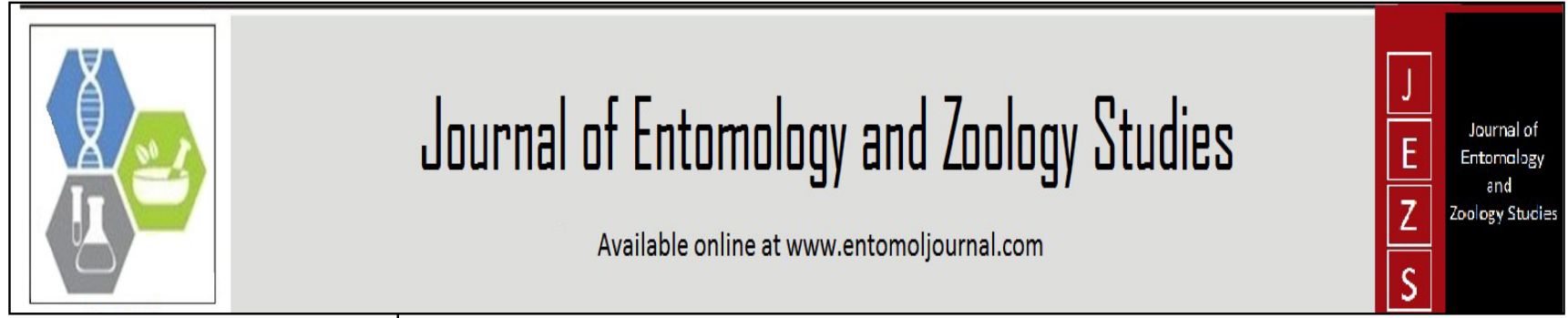

E-ISSN: 2320-7078 P-ISSN: 2349-6800 JEZS 2017; 5(3): 1720-1722 (C) 2017 JEZS

Received: 23-03-2017 Accepted: 24-04-2017

Mark Ian Cooper

Department of Biological Sciences, Rondebosch,

University of Cape Town
Correspondence

Mark Ian Cooper Department of Biological Sciences, Rondebosch, University of Cape Town

\section{Allometry of copulation in worm-like millipedes}

\section{Mark Ian Cooper}

\section{Abstract}

The prediction that copulation duration is longer when body mass increases was tested in juliform millipedes at the population-level by tabulating and correlating body mass $(0.6-8.5 \mathrm{~g} ; \mathrm{n}=1167)$ with copulation duration (34-206 $\mathrm{min} ; \mathrm{n}=391)$ in 8 southern African taxa: ord. Spirostreptida fam. Odontopygidae gen. Odontopyge $(\mathrm{n}=2 \mathrm{spp}$.), Spinotarsus $(\mathrm{n}=1 \mathrm{sp}$.) and fam. Spirostreptidae gen. Calostreptus ( $\mathrm{n}=1 \mathrm{sp}$.), Doratogonus ( $\mathrm{n}=1 \mathrm{sp}$.); and ord. Spirobolida fam. Trigoniulidae gen. Centrobolus $(\mathrm{n}=3 \mathrm{spp}$.) collected in 1989 (Zimbabwe) and 1996 (South Africa). Copulation duration and body mass were positively correlated across populations $(\mathrm{r}=-0.7626, \mathrm{~N}=11, \mathrm{P}=0.006347)$ and species $(\mathrm{r}=0.632 ; \mathrm{N}=8$; $\mathrm{P}=0.092734)$. This study contributes to the allometry of copulation.

Keywords: Allometry, copulation, millipede, prolonged

\section{Introduction}

Allometry is the growth of body parts at different rates, resulting in a change of body proportions. Allometry for metabolism has been investigated in southern African millipedes ${ }^{[1]}$. Allometry for sexual size dimorphism has been extensively investigated in juliform millipedes ${ }^{[2-4]}$. Although there are many studies on millipede mating behaviour no trend exists for the allometry of copulation in millipedes.

Millipede copulation is usually prolonged and differs between species and between populations ${ }^{[4]}$. In some millipedes, males and female mass correlates with copulation duration ${ }^{[6,7]}$. No trend has been demonstrated in juliform millipedes.

The present study investigates how copulation duration differs with mass $i$. $e$. the allometry of copulation between populations ${ }^{[2,5]}$. The prediction that copulation duration is longer when mass increases was tested in the present study by tabulating and correlating mass and copulation duration in 11 populations from 8 species of southern African worm-like millipedes.

\section{Material and Methods}

This study was conducted on southern African millipedes collected in Zimbabwe (February 1989) and South Africa (February and December 1996). Three variables were of interest: mean male mass, mean female mass and mean copulation duration.

\subsection{Body Mass}

Male and female mass variable scores in members of the families Spirostreptidae and Odontopygidae were calculated $(\mathrm{g})^{[5]}$. Male and female mass variable scores in members of the family Trigoniulidae millipedes were calculated ${ }^{[2,3]}$. Male body mass was compared to female body mass using a $T$-Test Calculator for 2 Independent Means.

Mean body mass was calculated by adding male and female body mass and halving the sum.

\subsection{Mean copulation duration}

Copulation duration (minutes) data of southern African millipedes were extracted from the literature $^{[2,3,5]}$. Mean copulation duration was calculated for each species.

\subsection{Statistical analysis}

Analysis was done on http://www.socscistatistics.com. Copulation durations and body mass were tested for a relationship using the Pearson Correlation Coefficient Calculator (http://www.socscistatistics.com/tests/pearson/Default2.aspx). Female and male body mass was plotted vs copulation duration for 11 populations using Statistica 13.2. 
A Probability-value was calculated from the Pearson's correlation coefficient score at

http://www.socscistatistics.com/pvalues/pearsondistribution.a spx.

\section{Results}

Copulation duration was longer when body mass increased. In the three families of millipedes both male and female mass and copulation duration were found for 11 populations (Table 1). Mass ranged an order of magnitude; from 0.6-8.5g. Mean male body masses were not significantly different (at $p<0.10$ ) from mean female body masses $(\mathrm{t}=0.27293 ; \mathrm{n}=11$; $\mathrm{P}=0.393851$ ). Mean female body mass positively related (at $p<0.01)$ to copulation duration $(\mathrm{r}=0.7388$; $\mathrm{N}=11$; $\mathrm{P}=0.009396$ ). Mean male body mass positively related (at $p<0.01)$ to copulation duration $(\mathrm{r}=0.7809$; $\mathrm{N}=11$; $\mathrm{P}=0.004552$ ). Hence mean body mass and mean copulation duration were positively related (at $p<0.01$ ) across the populations $(\mathrm{r}=0.7626 ; \mathrm{N}=11 ; \mathrm{P}=0.006347$; Fig. 1$)$ and positively related (at $p<0.10$ ) across species $(\mathrm{r}=0.632 ; \mathrm{N}=8$; $\mathrm{P}=0.092734$ ).

Table 1: Copulation duration and body mass $(\mathrm{g})$ in three families of millipedes.

\begin{tabular}{|c|c|c|c|c|}
\hline Family Species & Mean Copulation duration \pm S.D. (n) & Mean female mass (n) & Mean male mass (n) & Reference \\
\hline \multicolumn{5}{|l|}{ Odontopygidae } \\
\hline Odontopyge sp.3 (Vic. Falls) & $80.2 \pm 25.3(20)$ & $0.9(37)$ & $0.8(36)$ & [5] \\
\hline Odontopyge sp.3 (Marondera) & $85.6 \pm 16.6(19)$ & $1.6(18)$ & $1.24(26)$ & [5] \\
\hline Odontopyge sp. 3 & $82.9 \pm 21.0(39)$ & $1.29(55)$ & $0.98(62)$ & \\
\hline Odontopyge sp.2 (Marondera) & $66.0 \pm 11.2(28)$ & $1.9(41)$ & $1.4(20)$ & [5] \\
\hline Spinotarsus sp.1 (Marondera) & $92.3 \pm 18.6(19)$ & $0.7(35)$ & $0.8(17)$ & [5] \\
\hline \multicolumn{5}{|l|}{ Spirostreptidae } \\
\hline Doratogonus uncinatus (Mazowe) & $122.7 \pm 49,4(35)$ & $6.6(261)$ & $6.7(260)$ & [5] \\
\hline Doratogonus uncinatus (Hwange) & $205.8 \pm 60,8(25)$ & $8.5(31)$ & $7.9(23)$ & [5] \\
\hline Doratogonus uncinatus & $157.325 \pm 54,2(60)$ & $8.02(292)$ & $7.97(293)$ & \\
\hline Calostreptus sp. (Hwange) & $60.3 \pm 25,6(22)$ & $1.2(41)$ & $0.8(29)$ & [5] \\
\hline Calostreptus sp. (Sengwa) & $33.8 \pm 22.9(25)$ & $0.9(29)$ & $0.6(29)$ & {$[5]$} \\
\hline Calostreptus sp. & $47.05 \pm 24.3(47)$ & $1.0(70)$ & $0.7(58)$ & \\
\hline \multicolumn{5}{|l|}{ Trigoniulidae } \\
\hline Centrobolus inscriptus (Mtunzini) & $170 \pm 49.3(115)$ & $2.27(88)$ & $2.48(88)$ & {$[2,3]$} \\
\hline C. fulgidus (Richard's Bay) & $66.4 \pm 18.6(51)$ & $1.97(11)$ & $1.29(11)$ & {$[2,3]$} \\
\hline C. ruber (Port Shepstone) & $39.8 \pm 13.2(32)$ & $2.00(18)$ & $1.28(18)$ & {$[2,3]$} \\
\hline
\end{tabular}

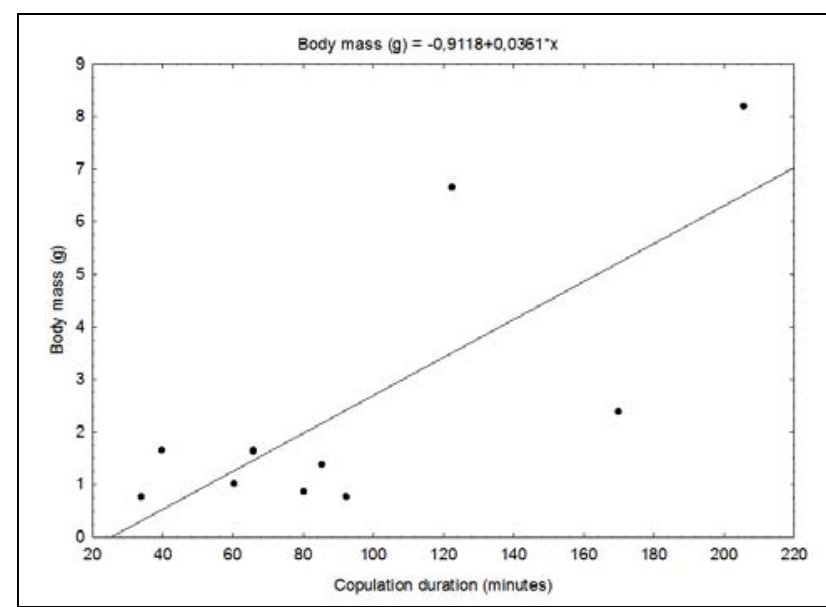

Fig 1: Scatterplot of body mass ( $\mathrm{g}$ ) against copulation duration (minutes) in worm-like millipedes.

\section{Discussion}

Body mass and copulation duration varies across populations and species of millipedes with a positive correlation between mass and copulation duration across the 11 populations from 8 taxa belonging to 3 families of juliform millipedes. Studies involving mass in millipedes showed a variation within populations and species $[1-5,7]$. The present study result questions the finding of larger males copulating for shorter duration in Polydesmidae ${ }^{[8]}$. It supports male control of the copulation duration in Spirostreptidae ${ }^{[9]}$. The appearance of larger females copulating for longer in Trigoniulidae is related to male size ${ }^{[6,7]}$.

\section{Conclusion}

Body mass in southern African worm-like millipedes positively relates to copulation duration.

\section{Acknowledgements}

Gary Cooper provided computer facilities for writing the article.

\section{References}

1. Frears SL, Webb PI, Telford SR. The allometry of metabolism in southern African millipedes (Myriapoda: Diplopoda). Physiological Entomology 2008; 21(3):212216.

2. Cooper MI, Telford SR. Copulatory Sequences and Sexual Struggles in Millipedes. Journal of Insect Behaviour. 2000; 13(2):217-230.

3. Cooper MI. Sexual size dimorphism and corroboration of Rensch's rule in Centrobolus Cook. Journal of Entomology and Zoology Studies. 2014; 2(6):264-266.

4. Cooper MI. Copulation and sexual size dimorphism in worm-like millipedes. Journal of Entomology and Zoology Studies. 2017; 5(3):1264-1266.

5. Telford SR, Dangerfield JM. Mating behaviour and mate choice experiments in some tropical millipedes (Diplopoda: Spirostreptidae). South African Journal of Zoology. 2015; 28(3):155-160.

6. Cooper MI. The affect of female body length on copulation duration in Centrobolus inscriptus (Attems). Journal of Entomology and Zoology Studies. 2017; 5(1):732-733.

7. Cooper MI. The influence of male body mass on copulation duration in Centrobolus inscriptus (Attems). 
Journal of Entomology and Zoology Studies

Journal of Entomology and Zoology Studies. 2016; 4(6):804-805.

8. Holwell GI, Allen PJD, Goudie F, Duckett PE, Painting CJ. Male density influences mate searching speed and copulation duration in millipedes (Polydesmida: Gigantowales chisholmi). Behavioural Ecology and Sociobiology. 2016; 70(8):1381-1388.

9. Telford SR, Dangerfield JM. Males control the duration of copulation in the tropical millipede Alloporus uncinatus (Diplopoda: Julida). South African Journal of Zoology. 2015; 29(4):266-268. 